\title{
Dimensões da Governança da Água no Nordeste Brasileiro
}

Bismarck Oliveira da Silva

Mestrando no Programa de Pós-Graduação em Estudos Urbanos Regionais do Departamento de Políticas Públicas da Universidade Federal do Rio Grande do Norte. Email: bismarck.oliveirasilva@gmail.com

José Gomes Ferreira

Sociólogo, Instituto de Ciências Sociais da Universidade de Lisboa/Programa de Pós-Graduação em Estudos Urbanos e Regionais do Departamento de Políticas Públicas da Universidade Federal do Rio Grande do Norte. Email: jose.ferreira@outlook.com.com

\section{Rayane Teixeira de Lira dos Santos}

Mestrando no Programa de Pós-Graduação em Estudos Urbanos Regionais do Departamento de Políticas Públicas da Universidade Federal do Rio Grande do Norte. Email: rayane.cpacred@gmail.com

Resumo: A mudança climática, o aumento de população e o adiar das políticas de saneamento colocam a cada dia mais pressão sobre os recursos hídricos, expondo suas desigualdades geográficas e sociais. Nesse contexto, o debate sobre a governança da água vem assumindo cada vez mais centralidade e atualidade, considerando diversos autores que o problema não é tanto de escassez, mas de uma crise de governança. No Brasil ganha maior destaque em momentos de dificuldades em abastecer as populações. O país tem seu diagnóstico feito quanto às dificuldades em implementar um modelo de governança que garanta maior eficácia às políticas, maior participação social e a escala de participação que estimule proximidade do cidadão com os problemas. O Nordeste tem um histórico de flagelo das secas, constituindo-se como elemento simbólico presente na identidade desta região. A resposta ao problema tem sido essencialmente encarada na perspectiva da convivência como semiárido, deixando de lado uma multiplicidade de questionamentos que envolvem todo o ciclo da água. Se, de um lado, é importante e fundamental uma abordagem transdisciplinar que faça o diagnóstico dos problemas, aponte soluções e proceda ao planejamento, de outro lado, é fundamental uma abordagem a partir das políticas públicas apontadas à gestão de mananciais, serviços e usos de água, saneamento básico, mas também de governança.

GT 9: Água, território, redes geográficas e governança 


\section{Introdução}

A água vem assumindo cada vez maior centralidade política, técnica, econômica e social justificada pela crescente pressão sobre seus usos, assim como pela contaminação e ameaça climática e pela forma como é social e geograficamente distribuída (JACOBI \& GRANDISOLI, 2017). Não admira, pois que se veja transformada no maior alvo dos conflitos ambientais (RIBEIRO et al, 2017). Diante desse cenário, o acesso ao recurso e à infraestrutura fundamental de abastecimento e esgotamento sanitário são igualmente alvo de intenso debate e disputas que extravasam o domínio ambiental, entrando no debate sobre cidadania, dignidade humana e valor econômico da água (HELLER \& CASTRO: 2007), assim como sobre justiça socioambiental e direito à cidade (LEFEBVRE, 2008; HARVEY, 2009), debate este muito presente no Brasil.

No sentido de fazer face ao problema, têm sido implementadas medidas de natureza diversa. $\mathrm{A}$ Lei 9.433 de 8 de janeiro de 1997, veio justamente oferecer um campo mais amplo aos recursos hídricos do Brasil, tratando o assunto de forma mais articulada, assim, identificando a preocupação com o tema da água, devido ao seu desperdício nos últimos anos. O reforço a necessidade de ações adequadas para a proteção das áreas dos mananciais e medidas que garantam de forma eficiente o uso da água e o seu desperdício. Possui um modelo descentralizado e participativo de gestão dos recursos hídricos brasileiros e nos mostra a necessidade de que quem possui mais capacidade de tomar decisões sobre a administração daquelas águas, é quem se encontra mais próximo, ou seja, seus principais usuários. É nesse contexto, que os comitês de bacia se apresentam como um órgão fundamental, promovendo a articulação da sociedade civil com poder público, atividades econômicas e domínios do conhecimento e da técnica. Porém, seu funcionamento e eficácia requer atenção pois identifica-se ainda a carência de recursos e da participação de todos (AMORIM, 2016; RIBEIRO et al, 2017).

Não menos importante é o esforço realizado na promoção da educação ambiental e sensibilização de jovens e adultos, ainda assim é uma área muito incipiente (JACOBI, 2017). E alguns esforços no sentido de avaliar a pressão das atividades humanas sobre os ecossistemas, medida através de índices como a pegada hídrica ou carbônica (LEÃO\& JACOBI, 2016). Ainda assim, persistem diversos bloqueios à governança.

Para se ultrapassarem as dificuldades é necessária uma visão mais abrangente e transversal, e um amplo empenhamento dos decisores e gestores públicos, mas também das universidades, organizações do setor e usuários. Essa transversalidade implica que a gestão de recursos hídricos seja encarada em todo seu ciclo e não de forma segmentada como por vezes acontece, apresentando de um lado a gestão dos mananciais e de planejamento, de outro lado os problemas de poluição e a falta de saneamento básico, e para além disso, de medidas que permitam lidar com a crise hídrica que ciclicamente afeta várias regiões do Brasil. 
A região Nordeste é tradicionalmente afetada por secas prolongadas, seguidas de inundações provocadas pelo caráter torrencial e concentrado das chuvas. A referida região mantém um profundo atraso no fornecimento de serviços de saneamento básico, em matérias como a coleta e tratamento de esgoto e as perdas de água na distribuição (FIGUEIREDO \& FERREIRA). A tudo isso, se adiciona a vocação artificial de alguns territórios para produção de frutos tropicais destinados a exportação e com elevada pegada hídrica (CRUZ, 2014). Em termos socioculturais, a região se caracteriza pela permanência de vínculos e favores clientelares, numa teia de poderes informais que contaminam a estrutura da administração pública, em particular, decisões em matéria de gestão e uso da água. Referimo-nos ao chamado coronelismo e clientelismo geralmente associado a contextos rurais e com expressão na chamada "indústria da seca", pela instrumentalização da seca pelos poderes político-econômicos informais, com influência nas opções da administração pública (CHACON, 2007; GUIMARÃES, 2016).

Com base neste enquadramento, é nosso objetivo identificar e analisar as principais características da governança da água no Nordeste, designadamente, possíveis bloqueios, primeiramente remetendo para o enquadramento com a situação brasileira sobre o tema e em seguida para o debate dos domínios que marcam a definição de prioridades das políticas públicas regionais e das dinâmicas sociais. A proposta se insere numa pesquisa de maior amplitude que analisa e discute a temática da seca e da gestão dos recursos hídricos.

\section{Metodologia}

A nossa leitura sobre a governança dos recursos hídricos inclui três dimensões principais. A saber, a dimensão mais estritamente associada ao setor e que, grosso modo, a partir de 1997 integra a Lei 9.433/1997, de 8 de Janeiro instituiu a Política Nacional de Recursos Hídricos e criou o Sistema Nacional de Gerenciamento de Recursos Hídricos em 2000, que criou a Agência Nacional de Águas (ANA). A água (superficial) é considerada definitivamente como um bem de domínio público e recurso natural limitado, dotado de valor econômico. Sua gestão tem como unidade de atuação a bacia hidrográfica e deve proporcionar usos múltiplos das águas, de forma descentralizada e participativa, com o envolvimento do poder público, usuários e comunidades. Os Comitês de Bacia assumem um papel essencial, na medida em que representam os usuários e a sociedade civil e a quem cabe elaboração dos planos de bacia hidrográfica. Na política de recursos hídricos os rios federais são geridos pela União, constituindo-se um Comitê e/ou Agência de Bacia interestadual, e os rios estaduais são da competência dos estados, exceto se existir alguma intervenção da União, por exemplo, no financiamento de uma barragem, a qual passará a ser gerida pelas entidades federais.

Em nossa análise incluímos igualmente os serviços de saneamento básico conectados com a água e esgotamento sanitário, tomando como ponto de partida a aprovação da Lei № 11.445 de 
5/1/2007, que estabelece diretrizes nacionais para o saneamento básico e definiu uma Política Nacional de Saneamento Básico. Embora se tome apenas duas dimensões, o saneamento inclui o conjunto de serviços, infraestruturas e instalações de abastecimento de água, esgotamento sanitário, limpeza urbana e manejo de resíduos sólidos e drenagem de águas pluviais urbanas. $\mathrm{O}$ saneamento básico registra em todo país um atraso considerável em sua concretização, designadamente na implementação de redes de coleta e estações de tratamento de esgotos. O problema resulta tanto da questão da invisibilidade das redes, que não dando votos são colocadas na agenda pública, mas que nem sempre compõem a agenda de prioridades políticas, quanto da falta de meios financeiros e humanos dos municípios e da falta de articulação entre estes, só para se citarem alguns motivos. Daqui se agrava a condição social de muitas populações, colocando em risco sua saúde e bem-estar.

Por último, face à especificidade do Nordeste incluímos igualmente a dimensão que corresponde ao combate à desertificação e convivência com a seca. Ainda que se considere a Lei 13.153, de 30/07/2015, que institui a Política Nacional de Combate à Desertificação e Mitigação dos Efeitos da Seca, a convivência com o semiárido nordestino, que inclui todo o Nordeste e norte de Minas Gerais, tem pelo menos um século de existência. Também neste caso se fez sentir o efeito do alargamento da temática ambiental à sociedade civil e ciência propulsionada pela Cimeira do Rio e iniciativas seguintes. Importa mencionar que, apesar das principais áreas suscetíveis à desertificação do semiárido corresponderem a $16 \%$ do território nacional, a seca tem igualmente atingido outras regiões do país (CGEE, 2016).

Com relação aos procedimentos, a pesquisa envolve a seleção de artigos científicos; obras sobre a temática da água e sobre a região; seleção e análise de políticas públicas; coleta de estatísticas sobre saneamento básico e caracterização sociodemográfica; a realização de seminários sobre Seca e Gestão de Recursos Hídricos no Nordeste Brasileiro, com a participação de diversos especialistas e gestores públicos; e a realização de entrevistas semiestruturadas a atores-chave. $\mathrm{O}$ artigo apresenta apenas parte da pesquisa realizada, em que se identificam as características estruturais que indicamos como estando a atrasar a implementação de medidas e políticas. Em outros artigos mostramos o processo histórico e um momento atual no que se refere à seca e saneamento básico (FERREIRA \& FIGUEIREDO, 2016; FIGUEIREDO \& FERREIRA, 2017). A informação recolhida em cada um dos procedimentos será analisada qualitativamente e quantitativamente, de modo a integrar comunicações a congressos, artigos e outras publicações. No final do ciclo de conferências pretendemos publicar um livro com as contribuições dos intervenientes, integrando igualmente os conteúdos recolhidos através dos outros procedimentos.

A análise realizada tem presente a influência do processo histórico e seu enraizamento como um bloqueio, todavia, nossa análise incide com maior acentuação sobre o período posterior à aprovação da Lei 9.433/1997, de 8 de Janeiro que instituiu a Política Nacional de Recursos Hídricos e cria o Sistema Nacional de Gerenciamento de Recursos Hídricos, e posteriormente 
dará ênfase ao período posterior à aprovação da Lei № 11.445 de 5/1/2007, que estabelece diretrizes nacionais para o saneamento básico e definiu uma Política Nacional de Saneamento Básico. Por outro lado, procuramos dar conta essencialmente do desenvolvimento das políticas e da dificuldade em lhe dar maior abrangência, por exemplo, envolvendo uma gama mais alargada de atores sociais, tanto através dos Comitês de Bacia, como de movimentos cívicos empenhados em conferir eficácia às políticas e diminuir as desigualdades sociais no acesso aos recursos hídricos e serviços de saneamento. Sobre esta matéria, são conhecidas as dificuldades em conseguir maior representatividade nos Comitês de Bacia, registrando-se dificuldades na sua instalação por falta de interesse em participar por parte da sociedade civil e seus representantes (AMORIM, 2016). Como sabemos, a dificuldade é estrutural e reflete uma crise generalizada de ativismo social e de cidadania, tendo o Brasil ao longo do seu percurso social e histórico apresentado um déficit participativo (ANDRADE \& JUCÁ, 2014).

\section{Impulso externo da governança das águas no Brasil}

O impulso para a política ambiental brasileira, e em particular a política da água, resultou de dinâmicas da política à escala global e da necessidade de dar resposta a anseios e necessidades da população em vários domínios, como sejam o saneamento, a saúde pública, a qualidade de vida e o bem-estar. É sabido que o processo de globalização da temática ambiental se intensificou na década de 1980, com a tomada de consciência da globalização do risco e degradação ambiental, dando origem a grandes transformações na forma como os cidadãos percepcionam os problemas ambientais e como respondem as empresas e as políticas públicas (VIOLA, 1999).

Já em matéria de água, o debate consolidou-se a partir de 1992, sobretudo ao abrigo das Nações Unidas, com a aprovação da Declaração de Dublin e dos documentos resultantes da Cimeira do Rio, nomeadamente no que tange a questões como a finitude, vulnerabilidade e importância do recurso para a vida humana e meio ambiente, assim como a definição da bacia hidrográfica como unidade de gestão e planejamento, e de uma visão integrada, que promova a qualidade das massas de água e dos ecossistemas adjacentes, fortalecida pelo contributo da ciência, da participação social e da aposta na transparência dos processos decisórios, no tocante a necessidade de novos modelos participativos e do contributo dos diferentes atores sociais (NAÇÕES UNIDAS, 1992; SCHMIDT, FERREIRA \& PRISTA, 2015). Tendo-se assumido igualmente questões como o valor cultural, social e econômico da água e a sua configuração não só como recursos naturais, mas como direitos humanos, que devem ser promovidos, de modo a reduzir as desigualdades sociais, garantir o acesso universal e equitativo à água, saneamento e higiene, reduzindo assim a vulnerabilidade das populações mais carenciadas e protegendo 0 ambiente (NAÇÕES UNIDAS, 2015). 
No caso do Brasil foi igualmente determinante, por um lado, a necessidade de dar resposta aos problemas comuns a bacias transfronteiriças, que exigem especial entendimento e cooperação dos atores envolvidos na gestão e nos problemas dela decorrentes. Mas também, a necessidade de internamente dar respostas e encontrar entendimentos na gestão de suas bacias federais compartilhadas (RIBEIRO et al, 2017). Por outro lado, não deveremos deixar de contar com as pressões que internamente se expressam no sentido do país melhorar a sua performance nos serviços de saneamento e promoção da cidadania, em que, à semelhança do que sucede em praticamente toda a América Latina, se registra um atraso considerável no fornecimento de água e esgotamento sanitário às populações (CASTRO, HELLER \& MORAIS, 2015), que depois se reflete na saúde e bem estar, como exemplo, correspondendo a US\$1,00 (um) dólar investido em saneamento a US\$4,00 (quatro) dólares de poupança em serviços de saúde (TRATA BRASIL, 2016).

Mas o próprio Brasil também forçou a compromissos externos, dada a sua reserva de água doce e o peso que tem à escala do planeta. O Brasil pode orgulhar-se de deter $12 \%$ dos recursos de água doce do mundo, $68,50 \%$ dos quais, concentrada no Norte e apenas $3 \%$ na região Nordeste 0 que revela suas assimetrias (ANA, 2016). O problema está exatamente na sua distribuição geográfica e social, não chegando de forma adequada e frequente a todos os brasileiros, não somente residentes em zonas rurais ou favelas, pois nas cidades persistem igualmente "ilhas de exclusão" ou áreas irregulares (TRATA BRASIL, 2016). No caso Nordeste, não registra apenas maior vulnerabilidade social, em questões como o analfabetismo, renda do trabalho e desocupação, a região somente é ultrapassada pelo Norte no que se refere ao atendimento de água e esgoto: apresentando um percentual de atendimento total de água em 2015, respectivamente, de $73,35 \%$ e $56,90 \%$, para uma média nacional de $83,30 \%$; e um índice de atendimento de esgoto de $24,68 \%$ no Nordeste e apenas $8,66 \%$ no Norte, quando a média brasileira atingiu 50,26\%. Apresentando grandes variações entre os nove estados, por exemplo, o abastecimento de água não ultrapassou $56,20 \%$ no Maranhão, e a coleta de esgoto abrangeu apenas 9,51\% no Piauí (SNIS, 2017).

Vários estudos, como mostramos anteriormente, têm dado conta das dificuldades em implementar um modelo de governança efetivo na gestão dos recursos hídricos no Brasil, com ampla abrangência e capaz de se constituir como mecanismos antecipatório de resolução de conflitos e de melhoria da gestão e planejamento dos recursos hídricos. Faltando uma visão articulada que inclua a gestão dos mananciais, os serviços de água e esgotamento sanitário, e a convivência com o semiárido, faltando dessa forma, maior envolvimento e liderança da sociedade civil. Em estudo recente feito sobre a situação dos Comitês de Bacias hidrográficas de rios do médio São Francisco (GOMES, 2008), nos diz que estes comitês são recentes, e não possuem a capacidade de atuar de forma eficiente, pois além de possuírem estrutura precária, não conseguem trabalhar na solução de conflitos de forma mais concreta, enfrentando os problemas gerados pela pressão dos diferentes usos da água. Gomes (2008) ainda nos esclarece que os comitês acabam 
elaborando apenas projetos que não são levados a diante, não possuindo eficiência, o que ocasiona desinteresse e desmotivação por parte dos membros e, consequentemente, pela sociedade. Outro ponto identificado nas dificuldades dos mecanismos de participação é a falta de conhecimento por parte da população sobre o funcionamento e a forma de atuação destes mecanismos de controle democrático e participação popular, num espaço que deveria servir como local para discussões efetivas sobre a gestão dos recursos hídricos (GOMES, 2008). Estas dificuldades de funcionamento pela carência de recursos e participação efetiva (AMORIM, 2016; AMORIM et al., 2016), gera desinteresse e desmotivação, para uma população já carente de informação e de formação.

Esse processo, que Carvalho (2004) denomina de cidadania em negativo no caso brasileiro, configurou e ainda configura em um esvaziamento ético-político de um povo que primeiro não tem um lugar ainda consolidado no sistema político e segundo não despertou para a importância de sua participação na construção das artérias da cidadania como pilares das políticas públicas. Este problema, portanto, não deriva exclusivamente da representatividade, resulta também da crise generalizada de ativismo social e de cidadania que se faz sentir em particular no Brasil, país que sempre apresentou um déficit participativo (ANDRADE \& JUCÁ, 2014). A educação ambiental pode ter aqui um papel importante no estímulo à participação e sensibilização de jovens e adultos, ainda assim, é uma área incipiente a ser mais explorada (JACOBI, 2017).

\section{Especificidade da governança da água no Nordeste}

À escala nacional, o relatório da Organização para a Cooperação e Desenvolvimento Econômico OCDE (2015), sobre a Governança dos Recursos Hídricos no Brasil mostrou que existe uma grande diversidade de situações em todo o país e que existem capacidades distintas dos estados para gerenciar os recursos hídricos e interagir com o governo federal.

Como orientação, o referido documento defende que, para que as políticas de água sejam mais sustentáveis, devem ser inclusivas e efetivas, defendendo um sistema de governança multinível mais forte e capaz de conciliar as prioridades estaduais e federais e melhorar a capacitação em diferentes níveis de governo (OCDE, 2015). Suas principais conclusões indicavam problemas nas seguintes áreas: coordenação e meios - formulação e implementação da política altamente fragmentada, com lacunas na governança e falta de meios financeiros; escala funcional disfuncionalidade resultante da incompatibilidade entre as três esferas de governo e os limites hidrológicos; abordagens isoladas - visão setorial dos ministérios e órgãos públicos e falta de coerência política agravada pela quase ausência dos comitês de bacias municipais; coordenação intersetorial - o Conselho Nacional de Recursos Hídricos não tem desempenhado plenamente o seu papel de coordenação intersetorial; princípio do consumidor-pagador - baixas cobranças pelo uso da água, que raramente se baseiam em estudos de acessibilidade ou avaliação de impacto; 
disponibilidade e viabilidade de dados - varia entre estados, prejudicando a tomada de decisão; passar à prática - Comitês de Bacias com poderes deliberativos fortes, entretanto, com limitada capacidade de implementação; falta de capacitação - dos órgãos deliberativos e das administrações públicas dos diferentes níveis de governo, sobretudo nos estados; e falta de conscientização - imagem de "abundância de água" leva políticos e cidadãos a não dar atenção ao tema, permanecendo apenas como meramente setorial. (OCDE, 2015)

Uma análise mais detalhada permite concluir que no Nordeste intervêm dimensões específicas que podem estar a bloquear a governança das águas. Esta região é conhecida por suas secas cíclicas e prolongadas, mas também por ser densamente povoada quando comparada a regiões semiáridas. Tem historicamente sofrido com a seca, fome, morte de pessoas e gado, e com o drama dos refugiados ambientais, conhecidos como os retirantes pela literatura, por exemplo, através das obras de Graciliano Ramos e Rachel Queiroz; pela pintura de Candido Portinari; e pela sociologia de Gilberto Freyre (COELHO, 2014). Esta é igualmente uma região que mantém enorme atraso no fornecimento de serviços de saneamento básico, sobretudo em matérias com a coleta e tratamento de esgoto, e o destino final dos resíduos e perdas de água na distribuição, registrando grandes assimetrias em seu território e nos diversos contextos sociais (FIGUEIREDO \& FERREIRA). A seca não é apenas uma questão climática, faz parte da identidade cultural do Nordeste. A resposta tem sido dada priorizando a construção de infraestruturas, como sejam barragens, açudes e adutoras, mas também através de medidas assistencialistas, que procuram evitar o que ficou conhecido como a fuga dos flagelados, conhecidos como retirantes, que durante as secas de 1915 e 1932 motivou a criação de campos de concentração no estado do Ceará para impedir os flagelados famintos de chegarem a capital Fortaleza (NEVES, 2001).

Na mesma linha se inclui o debate sobre o acesso à água no Nordeste atrelado a um quadro da dominação sobre o território e sobre a posse da terra (AB'SÁBER, 1999; ALBUQUERQUE JUNIOR, 2011). Assim como transformações mais recentes, entre as quais, a promoção da agricultura familiar e o seu impacto na democratização do acesso à água e à propriedade fundiária, uma política que agora dá mostras de retrocessos, mas que deixou bons encaminhamentos quanto à autonomia hídrica dos novos agricultores e de renda familiar (MORAES et al., 2016). Apesar dos graves problemas no abastecimento de água para consumo e para o gado, núcleos como o vale do Baixo Açu, a partir de 1983 com a inauguração da barragem Armando Ribeiro Gonçalves, quando o que passou a ser o maior reservatório de água do Nordeste se transformou no principal polo de produção de fruta tropical para exportação, com elevada pegada hídrica (CRUZ, 2014).

A seca é o elemento central do patrimônio climático e simbólico desta região, afetando as atividades econômicas e o cotidiano das comunidades. Assumindo um papel decisivo na identidade do Nordeste entre a segunda metade do século XIX e as primeiras décadas do século $\mathrm{XX}$, de tal modo que a região ganha autonomia face ao Norte e se diferencia da luta política e 
simbólica contra a centralidade do Sul. O Nordeste é "filho das secas" e de toda uma série de imagens e textos, produzidos a respeito deste fenômeno, desde que a grande seca de 1877/1888 a transformou no principal problema social da região (CAMPOS, 2014; ALBUQUERQUE JR., 2011; SANTOS, 2013). Porém, a seca não apavora o Nordestino. "É um complemento à sua vida tormentosa, emoldurando-a em cenários tremendos. Enfrenta-a, estoico" (CUNHA, 1902). Até ao inicio dos anos vinte do século passado "os termos Norte e Nordeste ainda eram usados como sinônimos. A sua autonomia enquanto região nasce de um complexo processo de diferenciação em relação ao Norte, e de luta política e simbólica contra a centralidade do Sul, e de produção e reprodução de representações acerca do passado patriarcal dos engenhos, das agruras das secas (SANTOS, 2013). Apesar dessa construção simbólica a região somente começa a se institucionalizar a partir de 1942, como um recorte espacial do Norte.

Em a Geografia da Fome (1952), Josué de Castro faz uma leitura do impacto direto da seca nas populações das formas dominantes da exploração fundiária e da exploração da mão de obra sertaneja, denunciando "que a seca foi feita vilã do drama nordestino, acobertando as formas dominantes da exploração econômica que criaram e reproduziram a concentração das riquezas e do poder político, gerando miséria e dependência de milhares de sertanejos" (SILVA, 2003: 362). Para Castro (1952), os problemas do Nordeste não se resumem à seca em si, mas a incapacidade perante a seca leva ao conformismo e inércia das populações. Poucos anos depois, a partir de 1956, o economista Celso Furtado propunha, através do Grupo de Trabalho para o Desenvolvimento do Nordeste (GTDN), que a convivência com o semiárido nordestino deve alavancar o desenvolvimento da região (FERREIRA \& FIGUEIREDO, 2016), e não apenas apresentar mais propostas tecnológicas e de mitigação do problema, desmitificando a crença segundo a qual "a seca era responsável pelo subdesenvolvimento regional" (SILVA, 2003: 363). Porém, alertando para o fato do seu impacto econômico e social da seca se colocar como um obstáculo à sobrevivência da "unidade nacional", na medida em que a intensa migração nordestina teria efeitos negativos noutras regiões (PEREIRA, 2004).Tal como Castro, Furtado defendia que o problema da seca não era apenas climático, estava enraizado na divisão da propriedade fundiária, na organização econômica e na formação histórica-política (TAVARES, 2008 e 2011).

Naquela que é provavelmente a primeira iniciativa do poder político de dar resposta à situação de emergência gerada pela voracidade da seca de 1877, o governo implementou um plano de ajuda e amparo aos flagelados da seca, criando a primeira Comissão Nacional de Estudos dos Problemas da Seca, que durante anos desenvolveu ações de combate às secas, na sua maioria medidas paliativas que procuravam combater seus efeitos. O reconhecimento oficial do Nordeste enquanto região administrativa marca também a transição para uma intervenção mais concreta da União e dos Estados na redução dos problemas da seca, inicialmente pensada apenas como construção e manutenção de infraestruturas hidráulicas para abastecimento e irrigação. Primeiro a 
Inspetoria de Obras contra as Secas (IOCS), criado pelo Decreto № 7.619, de 21 de outubro de 1909, o primeiro órgão federal criado com o objetivo de sistematizar o combate da problemática no Nordeste. Em 1919 a IOCS passou a se chamar Inspetoria Federal de Obras Contra as Secas através do Decreto no 13.687, de 9 de julho, até que em 1945, pelo Decreto-Lei 8.846, de 28 de Dezembro, foi criado o Departamento Nacional de Obras Contra as Secas (DNOCS).

Até meados do século XX existia o entendimento, de que o problema da seca no Nordeste era somente a falta de água, e a partir disso suas ações estavam restritas apenas a construções hidráulicas (ANDRADE e NUNES. 2014.). Até à criação da SUDENE, o DNOCS foi a única instituição responsável em atender as populações durante as secas, com uma ação voltada para a construção de estruturas "hidráulicas" rurais: barragens, açudes, estradas, pontes, portos, ferrovias, hospitais, redes telegráficas e de energia elétrica (NUNES et al., 2014).

A criação destas instituições não terminaram os problemas sociais, econômicos e ambientais resultantes da seca, até por que intervinham essencialmente em termos de hidráulica agrícola. Porém, constituíram a primeira intervenção de grande dimensão, atenuando problemas como a fuga dos retirantes, que desde a década de 1940 não se repetiu como fenômeno de massas. 0 segundo impulso foi dado com as transformações da década seguinte, que ainda assim não alcançaram a convergência com o crescimento do Centro e Sul do Brasil. A mudança de paradigma não resultou apenas na criação de novas instituições, mais também com investimento nas ações de planejamento e com novas obras, as quais refletiram igualmente em um importante impulso a partir de 1952 com a criação do Banco do Nordeste do Brasil.

Em 1956 o presidente Juscelino Kubitschek criou o Grupo de Trabalho para o Desenvolvimento do Nordeste (GTDN), nomeando Celso Furtado para a coordenação - o objetivo era desenvolver o Nordeste com base na industrialização, elaborando o relatório "Uma Política de Desenvolvimento Econômico para o Nordeste": Três anos depois, em Fevereiro de 1959, Kubitscheck lançou a Operação Nordeste (OPENO) e criou o Conselho de Desenvolvimento do Nordeste (CODENO), nomeando igualmente Celso Furtado como Secretário Executivo. Em 1959 foi criada a Superintendência do Desenvolvimento do Nordeste (SUDENE), que até 1964 teve Celso Furtado como responsável, permitindo assim, colocar em prática o diagnóstico apresentado no seu livro "A operação Nordeste".

A SUDENE "completou a estruturação de um modelo de intervenção do governo central que obedecia aos princípios desenvolvimentistas e respondia aos anseios regionais" da época (UDERMAN, 2015). A criação da SUDENE pretendia igualmente dar resposta às inquietações de que o DNOCS era refém do latifúndio e dos coronéis, que impunham um modelo de caráter rural/feudal, com o objetivo de perpetuarem o poder econômico e político e usar o atraso regional a seu favor (RIBEIRO, 1995; NUNES et al., 2014). A SUDENE surgiu igualmente face à "ação coletiva, organizada, responsável e consciente, na busca de conseguir decisões capazes de promover o desenvolvimento do Nordeste", e "de uma série de movimentos políticos, sociais e da 
Igreja Católica nordestina, sendo um produto direto do GTDN, Operação Nordeste e do CODENO" (SILVA FILHO, 2009). Acrescido a isso, teve uma tentativa de equilíbrio de forças entre Pernambuco e Ceará, uma vez que as suas capitais garantiam, respectivamente, a sede da SUDENE e DNOCS.

Mas a SUDENE ainda enfrentava as forças políticas ideológicas dos grandes empresários, e como afirma Diniz (2009), assumindo uma postura que incluía não só o planejamento, mas a infraestrutura, a reestruturação agrícola, colonização, desenvolvimento industrial e mineral, saúde pública, oferta de alimentos, levantamentos cartográficos, etc., presentes no I Plano Diretor sofreu fortes reações, não só no Conselho Deliberativo, mas no congresso, pois algumas de suas propostas tocava em temas que remetiam a Reforma agrária, e precisou somente disto para o atraso de sua aprovação. Em decorrência do Regime Militar, as linhas de frente de ação foram mudadas, focando em apenas duas: expansão da infraestrutura (transportes, energia elétrica e saneamento) e suporte à industrialização.

Efetivamente, a criação do Banco do Nordeste do Brasil, do GTDN (1956) e SUDENE (1959), definem um arranjo institucional que "desprezava o rural e os traços feudais do arranjo institucional do DNOCS" (NUNES et al., 2014). Impõe-se assim uma nova dinâmica de forças regionais, mas que gradualmente mostram que coronelismo e clientelismo não foram eliminados; não deixaram de ter base rural; e passaram a ter uma base urbana (CHACON, 2007). Aliás, por esse motivo, considera Guimarães (2008), têm dominado obras hidráulicas descoladas de um projeto de desenvolvimento regional, permitindo a construção da maior obra de açudagem do mundo, em muitos casos com infraestruturas ociosas de obras por concluir. $O$ autor refere-se sobretudo à transposição das águas do rio São Francisco, a qual sugere que a indústria da seca tem outro foco e escala, estando hoje voltava à indústria da construção de grandes obras (GUIMARÃES, 2008 e 2016).

Ainda assim, têm-se registrado mudanças na governança da seca, sobretudo quanto as estratégias de convivência com o semiárido, com maior envolvimento da população em processos decisórios, adquirindo um papel de protagonismo e ganhando maior capacidade adaptativa (MANCAL, 2016). Todavia, a insistência em grandes infraestruturas sem ser garantido o seu funcionamento futuro, pelo provável acentuar da mudança climática (GUIMARÃES, 2008; MARENGO, 2010; MARENGO et al, 2016), paralelamente a medidas emergenciais, com destaque para o abastecimento através de carros-pipa, mantêm e alargam antigos vínculos e redes de dependência, que por sua vez se subjugam ao interesse político e pessoal. Quanto às medidas assistencialistas, como o programa Bolsa Estiagem e mesmo a Aposentadoria Rural, entre outros, ao entrarem na esfera dos direitos de cidadania podem estar mais protegidas da arbitrariedade dos poderes informais, no entanto, não deixam de estar ameaçadas com a viragem política do país. Ainda assim, de salientar, que todo este conjunto de medidas - grandes infraestruturas, medidas emergenciais de abastecimento de água e medidas de apoio financeiro em situações de 
seca - estacaram o fenômeno dos retirantes e de convulsão social derivada da seca. Tal não significa que por vezes não seja difícil a articulação entre os organismos da federação e os estaduais e entre estes as empresas públicas que operam os sistemas e os municípios.

O Programa Um Milhão de Cisterna é uma iniciativa da ASA - Articulação no Semiárido Brasileiro com características de política pública, que apoia a construção de cisternas individuais como proposta de convivência com o semiárido, uma política pública que começou de baixo para cima, alargando a sua execução a outras medidas, mas mantendo a matriz da coordenação e implementação pela sociedade civil (FERREIRA \& FIGUEIREDO, 2016). Em concreto através da ASA, uma rede formada por mais de três mil organizações da sociedade civil que atuam no semiárido- sindicatos rurais, associações de agricultores e agricultoras, cooperativas, ONG's, Organização da Sociedade Civil de Interesse Público, etc.

Em suma, apesar dos avanços na gestão dos recursos hídricos, na convivência com o semiárido e na resolução dos problemas de saneamento básico persistem muitos obstáculos. Desde logo os já destacados interesses com origem na sociedade tradicional, mas que ressurgem em obras como a transposição do rio São Francisco, agora associando a chamada indústria da seca à indústria da construção de grandes obras públicas (GUIMARÃES, 2016). E analisando brevemente o caminho que as políticas públicas tomaram sobre a questão da seca e dos recursos hídricos t no Brasil, percebe-se que as intervenções públicas que ocorreram não resolveram o problema, pois eles associavam a raiz do problema a falta de água, quando na verdade, tratava-se de uma questão estrutural em consonância com as condições naturais. Por outro lado, diversos estudos dão conta dos disfuncionamentos do modelo de governança e das dificuldades em implementar novos mecanismos. Por exemplo, alguns estudos (AMORIM, 2016; RIBEIRO et al, 2016) identificam dificuldades de funcionamento dos órgãos gestores estaduais da água e dos Comitês de Bacia, quer por falta de meios humanos adstritos às instituições (ex. IGARN e AESA não possuem quadro de pessoal), assim como por falta de meios materiais/logísticos, financeiros e autonomia funcional, e por dificuldades de representatividade da sociedade civil fragmentada e pouco participativa.

Não podemos esquecer o peso do referido coronelismo e clientelismo, assim como o fato dos próprios indicadores sociais e econômicos puxarem "a região para trás" (FURTADO, 1984; FERREIRA \& FIGUEIREDO, 2016). Igualmente determinante neste modelo, a questão das escalas e das responsabilidades. A verticalização das decisões e a fraca tradição municipalista dificultam a concretização das políticas, que passam a depender demasiadamente das dinâmicas estabelecidas, assim como da herança de poderes informais na gestão da água e na influência que estes poderes exercem sobre os poderes formais. Relembre-se que esta região se tem caracterizado por vínculos e favores clientelares, numa teia de poderes informais que contaminam a estrutura da administração pública, em particular decisões em matéria de gestão e uso da água. Essas relações de poder geralmente associadas a contextos rurais e com expressão na chamada 
indústria da seca, pela instrumentalização da seca pelos poderes informais, baseado numa concepção com influência nas opções da administração pública (CHACON, 2007; GUIMARÃES, 2016). Foram de tal modo determinantes, que outrora muitas obras foram realizadas com recursos públicos, mas na verdade se destinavam a propriedades privadas ou seus usos foram apossados e controlados por grandes proprietários (ANDRADE \& NUNES, 2017).

\section{Considerações finais}

A crise hídrica atual, como tem sido chamada, deriva não só da escassez de água, mas acima de tudo, de uma crise humanitária, de governança (AGUDO, 2010 e 2013) e de falta de planejamento (EMPINOTTI; JACOBI, 2013). Para se ultrapassar este problema é necessária uma visão de todo o processo e numa perspectiva ampla de necessidades de usos, cuja água não se limite a satisfazer situações básicas, mas que promova a cidadania e as oportunidades seja dialogante com outras áreas seja com as políticas públicas. É necessária uma nova abordagem que reconheça a importância não só dos aspectos meramente técnicos e políticos relacionados à água, mas também das dinâmicas sociais e culturais e a forma como interagem com o meio natural e influenciam as preferências e o conhecimento das populações, encarando a água como um ativo eco-social e um agente de socialização, ajustando igualmente os mecanismos de governança em face da respectiva escala, de modo a darem resposta aos problemas (AGUDO, 2010 e 2013; SOFOULIS, 2005).

São necessárias formas inovadoras de governança que envolva as comunidades e, sobretudo, que as estimulem a participar, o que passa pelo desenho das políticas e escala de participação, consolidando-se a gestão por bacia hidrográfica como fundamental, mas por vezes faz-se necessário atuar na micro-escala, levando em conta o conhecimento local dos problemas e dando primazia à interdisciplinaridade na análise das questões ambientais (JACOBI, 2017). E para que se efetive a participação popular nos Comitês de Bacias hidrográficas, é necessário e imprescindível capacitação sobre a gestão e efetivação do uso racional da água, para que as pessoas do município que irão administrar os comitês possuam o conhecimento de como solucionar os conflitos, e de motivar a população para a participação efetiva sobre a questão das águas no Brasil. A escala funcional é um aspecto central de seu funcionamento, dada à orgânica funcional e fronteiras administrativas entre competências federais, estaduais e municipais. Sem se atender essa disfuncionalidade dificilmente estaremos caminhando para um modelo de governança comum, pelo contrário, vamos divergir e alimentar cada vez mais visões setoriais e fragmentadas, necessitando de mais meios e obtendo menos resultados.

É igualmente essencial uma política de transparência e acesso à informação, que passe pela descodificação de informação e sua divulgação através de diversos meios, mas também por campanhas de sensibilização e de educação ambiental, que capacitem os cidadãos e os 
decisores (SCHMIDT, FERREIRA \& PRISTA, 2015, JACOBI, 2017). No Brasil a questão da informação e fiabilidade dos dados é um elemento crucial, sem o qual as políticas estão condenadas, assim como a confiança dos cidadãos relativamente às instituições.

O Nordeste tem neste referente um longo caminho a percorrer, desde logo pelo próprio passivo da governança no Brasil, e em particular por suas características. Relembramos o histórico do flagelo da seca e da criação de instituições públicas de resposta ao problema, que em sua trajetória se deram por vezes enviesadas pelo peso de sua dependência político-econômica. Ainda que se trate de uma pesquisa exploratória, o atraso na elaboração dos Planos Municipais de Saneamento Básico, de que tem dado conta o Instituto Trata Brasil, e a verticalização da resposta à seca, respondendo as infraestruturas ao DNOCS e o planejamento à SUDENE, intervindo nas suas áreas de atuação as instituições estaduais, mostram que os municípios brasileiros são pouco ou nada atuantes nesta matéria.

Sem essa base de atuação e resposta aos problemas, fica comprometido o envolvimento direto das populações, tanto na definição das políticas e sua execução, com em iniciativas de sensibilização e capacitação. Essa problemática revela outra, o da necessidade de efetiva articulação entre políticas de convivência com o semiárido, saneamento básico e gestão dos mananciais, assim como os setores que podem ser afetados por estes problemas, como sejam a saúde, o ensino, o desenvolvimento e emprego, mas também o turismo e a cultura. Essa articulação é muito recente, ganhando ânimo com o debate de alternativas tecnológicas ao aproveitamento da água, o chamado reuso da água tratada, mas ainda focada no interesse econômico desse reuso e não numa perspectiva de proteção dos ecossistemas, que ao mesmo tempo pode alavancar desenvolvimento, melhoria da saúde e qualidade de vida.

\section{Referências}

AB'SÁBER, Aziz Nacib. "Sertões e sertanejos: uma geografia humana sofrida". Estudos avançados 13.36. 7-59. 1999. Acesso em 22 de Abril de 2016 em http://www.scielo.br/pdf/ea/v13n36/v13n36a02.pdf

AGUDO, Pedro Arrojo. "El reto ético de lacrisis global del agua". Relaciones Internacionales, no. 12.7.1, 2009.

"I. Typology and roots of conflicts over water in the world". Jaume Declòs (coord.). Water, a right, not a commodity. Civil Society proposals for a public model of water services. Engineering without Borders. Calatunha, p.9-36. 2010.

. Lo público y lo privado em la gestión del agua. In: VIII Congresso Ibérico de Gestão e Planeamento da Água. Lisboa, Fundação Calouste Gulbenkian, 5-7, de dezembro de 2013.

Fundação Nova Cultura da Água. Saragoça. 2013. Acesso em 7 de Fevereiro de 2014 em http://www.fnca.eu/images/documentos/8-congreso-iberico/Conclusiones-8CIGPA-pt.pdf 
ALBUQUERQUE JUNIOR, Durval Muniz de. "A aridez das ideias: a questão ambiental do Nordeste em busca de práticas e discursos inovadores". (Mimeo). 2011. Acesso em 21 de Outubro de 2016 em http://www.cch.unimontes.br/edocampo/index.php/biblioteca?download=9:aaridez-das-ideias-durval-muniz

AMORIM, Alcides Leite de. Mecanismos de resolução de conflitos em bacias hidrográficas compartilhadas: o caso das Bacias dos rios Piranhas-Açu (Brasil) e Tejo. (Península lbérica). Tese apresentada ao Programa de Pós-Graduação em Recursos Naturais da Universidade Federal de Campina Grande como requisito parcial à obtenção do grau de Doutor em Recursos Naturais, 2016.

ANDRADE, Denise Almeida de; JUCÁ, Roberta Laena Costa. Participação Política no Brasil: Uma Reflexão Sobre as Manifestações Populares de Junho a Setembro de 2013 a Partir da Proposta da Democracia Deliberativa. Nomos,34.2, 2014.

ANDRADE, Jucilaine Aparecida de; NUNES, Marcos Antônio. Acesso à água no Semiárido Brasileiro: uma análise das políticas públicas implementadas na região. Revista Espinhaço| UFVJM, p. 28-39, 2017.

ASA. "Ações. P1MC". Articulação Semiárido Brasileiro. Acesso em 26 de Novembro de 2016 em http://www.asabrasil.org.br/acoes/p1mc

CAMPOS, José Nilson B. "Secas e políticas públicas no semiárido: ideias, pensadores e períodos." Estudos Avançados 28.82: 65-88. 2014. Acesso em http://www.scielo.br/scielo.php?pid=S0103-40142014000300005\&script=sci_arttext\&tlng=pt

CARVALHO, José Murilo. Cidadania no Brasil: o longo caminho. Rio de Janeiro: Editora Civilização Brasileira, 2004.

CASTRO, José Esteban, HELLER, Léo \& MORAIS, Maria da Piedade. O Direito à água como política pública na América Latina: uma exploração teórica e empírica. Brasília: IPEA, 2015.

CASTRO, José Esteban. "La producción y reproducción de ladesigualdad y lainjusticia social estructural: observaciones desde el campo empírico de los servicios públicos e senciales." Estudios Latinoamericanos. 36: 111-130, 2015.

CASTRO, Josué de. Geografia da fome. Casa do Estudante do Brasil, 1952.

CGEE. Desertificação, degradação da terra e secas no Brasil. Centro de Gestão e Estudos Estratégicos (CGEE). Ed: Brasília, 2016.

CHACON, Suely Salgueiro. O sertanejo e o caminho das águas: políticas públicas, modernidade e sustentabilidade no semiárido. Fortaleza: Banco do Nordeste do Brasil, 2007.

COELHO, Tiago da Silva. Candido Portinari e Graciliano Ramos: diálogos de Vidas Secas com os Retirantes. Baleia na Rede: Ed. Estudos em arte e sociedade, V. 1. 2015.

CRUZ, Rogerio Pires da. Mercados de terras agrícolas no semiárido nordestino: constituição, desenvolvimento e dinâmica recente. Tese de Doutorado do Programa de Pós-Graduação em Desenvolvimento Econômico do Instituto de Economia da Universidade Estadual de Campinas UNICAMP. 2014.

CUNHA, Euclides da. Os Sertões. Rio de Janeiro. Editora Nova Fronteira. 2016.

DINIZ, Clécio Campolina. Celso Furtado e o Desenvolvimento Regional. Nova Economia_Belo Horizonte_19 (2)_227-249_maio-agosto de 2009. Disponível em:

<http://www.scielo.br/pdf/neco/v19n2/a01v19n2> 
DUARTE, Regina Horta. "Com açúcar, com afeto": impressões do Brasil em Nordeste de Gilberto Freyre. Revista Tempo, Rio de Janeiro, 10.19: 125-147, 2004.

EMPINOTTI, Vanessa Lucena; JACOBI, Pedro Roberto. Novas práticas de governança da água? O uso da pegada hídrica e a transformação das relações entre o setor privado, organizações ambientais e agências internacionais de desenvolvimento. Desenvolvimento e Meio Ambiente, $\mathrm{v}$. 27, 2013.

FERREIRA, José Gomes, FIGUEIREDO, Fábio Fonseca. Promovendo a participação social e o debate sobre seca e gestão de recursos hídricos no Rio Grande do Norte. Anais do I Conidis. 2016. Acesso em 11/07/2017 em http://www.editorarealize.com.br/revistas/conidis/trabalhos/TRABALHO_EV064_MD1_SA14_ID24 49_24102016203512.pdf

FIGUEIREDO, Fábio Fonseca; FERREIRA, José Gomes. O Saneamento Básico no Nordeste e no Rio Grande no Norte: avanços e constrangimentos. Anais XII ENANPUR. 2017. Acesso em $11 / 07 / 2017$ em http://anpur.org.br/xviienanpur/principal/publicacoes/XVII.ENANPUR_Anais/ST_Sessoes_Tematic as/ST\%204/ST\%204.7/ST\%204.7-04.pdf.

FREYRE, Gilberto. Nordeste: A Influência da Cana sobre a Vida e a Paisagem do Nordeste no Brasil, Rio de Janeiro, José Olímpio. 1937.

FURTADO, Celso. O Nordeste: reflexões sobre uma política alternativa de desenvolvimento. Revista de Economia Política. Vol. 4, №3. 23. 1984.

GOMES, C. S. Comitês de bacias hidrográficas de rios do Médio São Francisco: possibilidades e desafios de gestão do uso da água. 2008. v, 97 p. Dissertação (Mestrado em Administração)Universidade Federal de Lavras, Lavras, 2008. Disponível em <http://repositorio.ufla.br/jspui/bitstream/1/2201/1/DISSERTA\%c3\%87\%c3\%830 Comit\%c3\%aas \%20de\%20bacias\%20hidrogr\%c3\%a1ficas\%20de\%20rios\%20do\%20M\%c3\%a9dio\%20S\%c3\%a3 o\%20Francisco.pdf>Acesso em: 17/07/17

GUIMARÃES JR, João Abner. "Discussão sobre secaSeminários SEMAPA "Seca e gestão de recursos hídricos no Nordeste brasileiro. Um desafio para as políticas públicas. Departamento de Políticas Públicas da Universidade Federal do Rio Grande do Norte, 13 de Outubro de 2016.

GUIMARÃES JR, João Abner. "Reforma hídrica do Nordeste como alternativa à transposição do rio São Francisco." Cadernos do CEAS: Revista crítica de humanidades 227: 80-88. 2016.

GUIMARÃES JR, João Abner. O Nascimento Da Indústria Das Secas No Brasil. Ecodebate. 2008. Acesso em 14 Julho de 2017 em https://www.ecodebate.com.br/2008/02/22/o-nascimento-daindustria-das-secas-no-brasil-artigo-de-joao-abner-guimaraes-jr/

GUTIÉRREZ, Ana Paula A., et al. "Drought preparedness in Brazil." Weather and Climate Extremes 3: 95-106. 2014. Acedido a 15 de Maio de 2016 em http://www.sciencedirect.com/science/article/pii/S2212094713000340

HARVEY, David. A liberdade da cidade. GEOUSP: Espaço e Tempo. N. 26, p. 09-18, 2009. Acesso em 14 de Julho de 2017 em http://www.geografia.fflch.usp.br/publicacoes/Geousp/Geousp26/09-18-HARVEY,David.pdf

HELLER, Léo; Castro, José Esteban. Política pública de saneamento: apontamentos teóricoconceituais. Engenharia Sanitário e Ambiental. Vol. 12. N. 3. 2007. 
IBGE. Estimativas da população residente no Brasil e unidades da federação com data de referência em 1ํ de Julho de 2016. Acesso em 15 de Outubro de 2016 em http://www.ibge.gov.br/home/estatistica/populacao/estimativa2016/default.shtm institucional e administrativa. 2009. Acesso em 14 de Julho em http://www.inad.com.br/publicacao/arquivos/20120730143856p_sudene_50_anos.pdf

MARSHALL, T. H. Cidadania, classe social e status. Rio de Janeiro: Zahar Editores, 1967.

JACOBI, Pedro Roberto. “Desafios à Governança e Participação Popular no Brasil”. In: Ribeiro, Wagner Costa. (Org.). Governança da ordem internacional e inclusão social. São Paulo:

Annablume, V. 2, p. 69-88. 2012.

"Planejamento e participação da governança da água no Brasil e suas interfaces com a governabilidade dos serviços de saneamento". In Leo Heller; José Esteban Castro. (Org.). Política pública e gestão de serviços de saneamento. 01ed.Belo Horizonte: UFMG/Fiocruz, V. 7 , p. 542555. 2013.

Pedro Roberto. Meio Ambiente, Riscos e Aprendizagem Social. Cadernos de Pesquisa: Pensamento Educacional, 10(26), 346-364. 2017.

JACOBI, Pedro Roberto; CIBIM, Juliana; LEÃO, Renata de Souza. Crise hídrica na Macrometrópole Paulista e respostas da sociedade civil. Estudos avançados, 2015, 29.84: 27-42. JACOBI, Pedro Roberto; Grandisoli, Edson. Água e Sustentabilidade desafios, perspectivas e soluções. São Paulo: IEE-USP e Reconectta, 2017.

LEÃO, Renata de Souza; JACOBI, Pedro Roberto. A contribuição de novas ferramentas para melhoria da gestão da água - uma análise da utilização da pegada hídrica pelo setor empresarial. In Pedro Roberto Jacobi (Org.). Conhecimento Interdisciplinar, Governança Ambiental e Sociedade. São Paulo: IEE-USP/PROCAM-USP, 2016.

LEFEBVRE, Henri. Espaço e Política. Belo Horizonte: Editora UFMG. 2008.

MANCAL, Ansu, et al. À espera da seca que vem: capacidade adaptativa em comunidades rurais do semiárido. Revista Brasileira de Estudos de População: 33.2: 257-281, 2016.

MARENGO, José A. "Vulnerabilidade, impactos e adaptação à mudança do clima no semi-árido do Brasil". Parcerias estratégicas 13.27: 149-176, 2010.

MARENGO, José A.; TORRES, Roger Rodrigues; ALVES, Lincoln Muniz. Drought in Northeast Brazil-past, present, and future. Theoretical and Applied Climatology: 1-12,2016.

MATALLO JÚNIOR, Heitor. Indicadores de desertificação: histórico e perspectivas. Cadernos UNESCO, 2001.

MORAES, Cássia, et al. Mudança do clima e os impactos na agricultura familiar no Norte e Nordeste do Brasil. InternationalPolicy Centre for Inclusive Growth, 2016.

NAÇÕES UNIDAS. Agenda 2030 para o Desenvolvimento Sustentável. 2015. https://nacoesunidas.org/pos2015/agenda2030/

Declaração de Dublin. 1992. Acesso em 14 de Julho de 2017 em

http://www.meioambiente.uerj.br/emrevista/documentos/dublin.htm

Transformando Nosso Mundo: A Agenda 2030 para o Desenvolvimento Sustentável.

Acesso em 11 de Julho de 2017 em https://nacoesunidas.org/pos2015/agenda2030/ 
NEVES, Frederico de Castro. Getúlio e a seca: políticas emergenciais na era Vargas. Revista Brasileira de História, 21.40: 107-129, 2001.

NUNES, Emanoel Márcio, et al. Políticas Agrárias e Agrícolas no Contexto do Desenvolvimento do Nordeste: evolução, desafios e perspectivas. Planejamento e Políticas Públicas, 43. 2014.

OCDE. Governança dos Recursos Hídricos no Brasil, OECD. Paris. 2015.

PEREIRA, Laurindo Mékie. A SUDENE e a questão regional: história e historiografia. XVII Encontro Regional de História-O lugar da História. ANPUH/SP. UNICAMP: Campinas, 6.,2004.

RIBEIRO, Darcy. O povo brasileiro. A formação e o sentido do Brasil. São Paulo. Companhia das Letras: $2^{a}$ edição, 1995.

RIBEIRO, Márcia Maria Rios; AMORIM, Alcides Leite de; FERREIRA, José Gomes; SCHMIDT; Luísa. Bacias hidrográficas compartilhadas no Brasil e na Península Ibérica: buscando consensos

SANTOS, Rafael José dos. "O engenho, a cidade e a seca: notas sobre a produção simbólica do Nordeste." Guavira Letras. № 17: 124-162. 2015. Disponível em Ihttp://marcacini.com.br/seer/index.php/guavira/article/download/101/83. Acesso em 21 de Outubro de 2016.

SCHMIDT, Luísa; FERREIRA, José Gomes; PRISTA, Pedro. Governança da Água na Europa e em Portugal: avaliação e perspectiva. Governança da Água no Contexto Iberoamericano: Inovação em processo, 125-150, 2015.

SILVA FILHO, Leonides Alves da. SUDENE: 50 anos. Uma abordagem política, institucional e administrativa. Acesso em 14 de Julho de 2017 em

http://www.inad.com.br/publicacao/arquivos/20120730143856p_sudene_50_anos.pdf

SNIS. "Série Histórica. Diagnóstico anual Água e Esgotos 2015". Acesso em 14 de Julho de 2017 http://www.snis.gov.br/aplicacao-web-serie-historica

SOFOULIS, Zoë. "Big water, everyday water: a sociotechnical perspective." Continuum: Journalof Media \&Cultural Studies. 19.4: 445-463, 2005.

TAVARES, Hermes M. Nordeste-1959: a Lei de Irrigação abortada. Cadernos IPPUR, 2008.

TAVARES, Hermes Magalhães. Estratégias de desenvolvimento regional. Da grande indústria ao Arranjo Produtivo Local? Revista Brasileira de Gestão e Desenvolvimento Regional, 2011.

TRATA BRASIL. Ranking do Saneamento Instituto Trata Brasil 2016. São Paulo. GO Associados/Instituto Trata Brasil. Disponível em

http://www.tratabrasil.org.br/datafiles/estudos/ranking/2016/relatorio-completo.pdf Acesso em 20 de Outubro de 2016.

UDERMAN, Simone. Políticas de Desenvolvimento Regional no Brasil: Limites de uma nova agenda para Nordeste. Revista Brasileira de Estudos Regionais e Urbanos, 2.2. 2015. via mecanismos de resolução de conflitos. In: Arlindo Philippi Jr e Maria do Carmo Sobral (Editores) Gestão Sustentável de Bacias Hidrográficas. Barueri, SP: Editora Manole, 2017.

VIOLA, Eduardo. A globalização da política ambiental no Brasil, 1990-1998. In: O agronegócio do Mercosul e a sua inserção na economia mundial, Anais do $37^{\circ}$ Congresso Brasileiro de Economia e Sociologia Rural. Brasília: Sober, 1999. 